\title{
Preparation of Activated Carbon from Lapsi Seed Stone and its Application for the Removal of Arsenic from Water
}

\author{
Rinita Rajbhandari ${ }^{1}$, Lok Kumar Shrestha ${ }^{2}$ and Raja Ram Pradhananga ${ }^{3^{*}}$ \\ ${ }^{1}$ Department of Science and Humanities, Pulchowk Campus, Institute of Engineering, Nepal. \\ ${ }^{2}$ National Institute of Material Science( NIMS), Tsukuba, Japan \\ ${ }^{3}$ Central Department of Chemistry, Tribhuvan University, Kathmandu, Nepal \\ *Corresponding author: rajaram@cdctu.edu.np
}

\begin{abstract}
Adsorption of arsenic by activated carbon prepared from locally available Lapsi seed stone is presented. Activated carbon has been prepared by carbonization of Lapsi seed stone (chorespondias axillaris, Roxb) in a nitrogen atmosphere at $400^{\circ} \mathrm{C}$. Chemical activation using a 1:1 ratio of Lapsi seed stone powder and zinc chloride followed by iron impregnation greatly enhanced the arsenic adsorption capacity for adsorption of arsenic from ground water. Activated carbon of dose $2 \mathrm{~g} / \mathrm{L}$ decreased the concentration of arsenic in water from $800 \mathrm{ppb}$ to below the interim guide line value of $50 \mathrm{ppb}$ of arsenic in drinking water of Nepal. The iodine number of raw carbon is quite low but chemical activation using 1:1 Lapsi seed powder and zinc chloride at $400^{\circ} \mathrm{C}$ increased the iodine number to $791 \mathrm{mg} / \mathrm{g}$. Iron impregnated activated carbon prepared from locally available Lapsi seed stones can be used in community level at point- of- use for treatment of arsenic contaminated ground water.
\end{abstract}

Keywords: activated carbon, arsenic removal, adsorption, chorespondias axillaris, iron impregnated carbon.

\section{Introduction}

Activated carbon is a porous material prepared from carbonaceous materials with simultaneous activation by chemical or physical methods. The application of activated carbon depends upon the surface area of activated carbon, pore size distribution and surface functional groups. Activated carbon with a desired porosity distribution is prepared from synthetic carbon precursor or lignocellulosic materials. Lignocellulosic materials composed of cellulose, hemi-cellulose and lignin cross linked in different ways. Previous research has shown that meso and micro-porosity in activated carbon manufactured from lignocellulosic materials reflects the botanical texture of the precursors. ${ }^{1}$ Activated carbon has been prepared from different lignocellulosic materials. Coconut shells and fruit stones are popular for many types of activated carbon. The fruit stone used are olives ton, cherry stones, peach stones etc. Preparation of activated carbon involves two steps, the carbonization of raw carbonaceous materials in an inert atmosphere and the activation of the carbonized product. In chemical activation, the carbonization and activation are accomplished in a single step by carrying out thermal decomposition of the raw material impregnated with certain chemical agents. Activation of carbon is used to enlarge the diameter of the fine pores and create new pores. The activated carbon can serve as ideal support media for iron impregnation, and iron impregnated material is known to be most effective adsorbent for arsenic. The selection of the precursor for the preparation of activated carbon depends upon 
availability, cost, carbon content, and ease of activation. Considering all these facts Lapsi (choerospondias axillaris) seed stone is selected as a precursor for preparing activated carbon in the present study. No report is available so far for the preparation of activated carbon from Lapsi seed stone ${ }^{2}$ (Choerospondias axillaris). Every year tons of Lapsi seed stone are generated as agricultural waste matter and are use only as fuel in brick kilns. The photograph of a Lapsi seed stone is shown in figure 1. Lapsi is native to Nepal ${ }^{3}$. It is a wild large deciduous and dioecious plant belonging to the family Anacardiaceae. The Lapsi tree is reported in three hundred village development communities of Nepal, forty thousand trees has been producing fruits and five hundred thousand new plants have been planted. The edible part of the fruit (skin and pulp) comprises $71 \%$ and seed stone is $29 \%$.

The presence of Arsenic above WHO guideline in ground drinking water of the Terai region of Nepal has become a major health concern ${ }^{4}$. Arsenic contamination and its mitigation measurements came into light in the 1980s when alarmingly high concentrations of arsenic was found in the tube wells of West Bengal of India and Bangladesh which had created a great havoc, and was also considered as the world's biggest environment disaster. Department of water Supply and Sewerage (DWSS) with assistance from WHO/Nepal conducted a systematic study on the contamination of arsenic in the ground water of the Terai region of Nepal. In the six districts of the Terai region of Nepal, water from the tube wells (TW) are contaminated with arsenic in a level higher than the safe limit set by WHO for drinking purpose ${ }^{5}$. Modifications of the known adsorbent are necessary for enhancing the efficiency of removing arsenic from arsenic contaminated ground water. ${ }^{6-8}$ For wide spread use of the adsorption method the cost of the adsorbent should be low. Such a low cost adsorbent could only be produced from locally available resources. Among many types of adsorbent materials, activated carbons are the most widely used for water treatment owing to their versatile adsorption capacity and low cost.

The objective of the present work is to investigate the effect of surface modification and iron impregnation on the adsorption of arsenic from arsenic contaminated ground water. The paper highlights the preparation, surface modification and iron impregnation of activated carbon from Lapsi seed stone (Choerospondias axillaris), and adsorptive removal of arsenic from ground water.

\section{Experimental}

\section{Materials}

Lapsi seed stones were obtained from the Kalimati vegetable market. Zinc chloride of purity higher than $98 \%$ was from Qualigen. The nitrogen is of ultra high pure (UHP).

\section{Preparation of iron impregnated Activated carbon}

Lapsi fruits were collected from the vegetable market at Kalimati, Kathmandu. The fleshly part was removed and the seed stones were washed several times with distilled water and dried in electric oven at $110^{\circ} \mathrm{C}$, crushed and grinded in electric grinder and sieved to a uniform size of 1.0-2.0mm. The Lapsi seed granule (LSG) were then chemically activated with $\mathrm{ZnCl}_{2}$ in the ratio of 1:1 for 24 hours. The mixture was dehydrated in a hot plate and carbonised in a tube furnace (Accumax, India) under nitrogen flow of $100 \mathrm{ml}$ per minute at $400^{\circ} \mathrm{C}$ for four hours. The activated carbon was then cooled to room temperature and washed with deionised water to remove remaining chemicals. Then the samples were stirred for $1 \mathrm{~h}$ with $0.1 \mathrm{M} \mathrm{HCl}$ and washed 
with freshly prepared distilled water untill free of zinc ions and dried. $2 \mathrm{~g}$ of dried activated carbon was treated with $8 \mathrm{~mL}$ of $2 \mathrm{M} \mathrm{Fe}\left(\mathrm{NO}_{3}\right)_{3} .9 \mathrm{H}_{2} \mathrm{O}$ solution and $0.1 \mathrm{~mL}$ of $\mathrm{M} \mathrm{NaOH}$ was added. The slurry was heated to $100^{\circ} \mathrm{C}$ for 12 hours, cooled washed and dried. This iron impregnated carbon was used for arsenic adsorption.

\section{Determination of Iodine Number}

$100 \mathrm{mg}$ of charcoal was added to $5 \mathrm{~mL}$ of $5 \% \mathrm{HCl}$ and boiled and cooled. To the cold solution, $10 \mathrm{~mL}$ of $0.1 \mathrm{~N}$ iodine solution was added, shaken for $30 \mathrm{sec}$ and filtered. The filtrate was titrated with $0.1 \mathrm{~N}$ sodium thiosulphate solution.

\section{Adsorption of Arsenic}

$0.05 \mathrm{~g}$ of iron impregnated activated carbon was equilibrated with $25 \mathrm{~mL}$ synthetic water samples containing different concentrations of Arsenic in Erlenmeyer flasks, and the concentration of arsenic in the filtrate was determined by standard SDDC method.

\section{Results and Discussion}

The photograph of Lapse seed stone is shown in figure 1. It is a waste material and currently used as a fuel in brick kilns. Every year tons of Lapsi seed stone are generated as waste material. It contains mainly cellulose, hemi-cellulose and lignin. The proximate analysis of Lapsi seed stone powder is given in table 1. The fixed carbon percentage of Lapsi seed stone power is $32.8 \%$ which is quite reasonable for the lignocellulosic material. The FTIR of Lapsi seed powder is shown in figure 2 . The IR spectra clearly show the presence of $-\mathrm{OH}$, lactone, alcoholic and etherial group in the material. The quantification of the surface functional group obtained from by the Boehm method is given in table 2 . The presence of oxygen containing surface function groups in the activated carbon from choerospondias axillaries seeds can acts as a site for iron loading. Hence the activated carbon is impregnated with iron (III). The iron impregnated activated carbon has high adsorption capacity for arsenic.

Figure 3 represents the FTIR spectra of carbon prepared from carbonization of Lapsi seed stone powder in ultra pure nitrogen atmosphere at $400^{\circ} \mathrm{C}$. The FTIR spectra were recorded in $\mathrm{KBr}$ dispersion method. The FTIR shows the presence $-\mathrm{COOH}$, phenolic and lactone groups in the surface of carbon

The Scanning electron microscope (SEM) picture of activated carbon is shown in figure 4 . The picture shows the highly porous characteristics of activated carbon with full of cavities like a honey comb structure. The porous surface morphology of the prepared carbon is a positive point for adsorption of arsenic. The micro and messo pores in activated carbon acts as adsorption sites for adsorption of metal and other pollutant in water. The concentration of these pores can be increased by thermal and chemical activation. Chemical activation using zinc chloride at elevated temperature increases the messo pores in carbon.

The iodine numbers of carbons prepared from Lapsi seed stone powder in different conditions are given in table 2. If we look at the table it clearly shows that higher percentage of zinc chloride and high temperature is favorable to increase the iodine number. The ratio of $\mathrm{LSP}: \mathrm{ZnCl}_{2}$ to $1: 1$ seems to be optimum. The decrease in amount of zinc chloride for chemical activation decreases the iodine number. The increase in zinc chloride above $50 \%$ increases the iodine number marginally. The optimum temperature is found to be $400^{\circ} \mathrm{C}$. Increase in carbonization 
temperature increases the iodine number but energy consumption at higher temperature is high. So a carbonization temperature of $400^{\circ} \mathrm{C}$ seems to be very good choice for preparation of activated carbon with sufficient messo pores for adsorption of iodine. The iodine number determination is a simple and quick test, giving an indication of the internal surface area of the activated carbon, in many activated carbon materials the iodine number (expressed in milligrams of iodine per gram of carbon) is close to the Brunner Emmet Teller (BET) surface area. ${ }^{1}$

The efficiency of iron impregnated activated carbon for adsorptive removal of arsenic (III) from synthetic water sample is shown in figure 4 . The initial concentrations of water arsenic in water sample were 200, 400 and $800 \mathrm{ppb}$. After adsorption with iron impregnated activated carbon the arsenic concentrations decrease to 9.9, 15 and $15 \mathrm{ppb}$. These values are below the interim guideline value of arsenic in drinking water of Nepal. The carbon dose for arsenic adsorption was set to $2 \mathrm{~g} / \mathrm{L}$.

\section{Conclusion}

The Lapsi stones seed, a waste agricultural product, can be carbonized to obtain activated carbon and which after iron impregnation can be used as efficient adsorbent for removing As(III) from water. Iron impregnation greatly enhances the adsorption capacity for the adsorptive removal of As (III) from ground water. This low cost adsorbent prepared from locally available waste seed can be used by community at the point of use to get rid of arsenic pollution in ground water.

\section{Acknowledgement}

The author/s would like to extend thanks to National Institute of Material Science, Japan for allowing the use of the SEM facilities of the institute. One of us (RR) is thankful to IOE for granting study leave and UGC for a partial scholarship to carry out this work.

\section{REFERENCES}

1. Kundu,S., and Gupta A.K.; 2005 Sorption Kinetics of As $(V)$ with Iron Oxide Coated cement - A new Adsorbent and its Application in the removal of Arsenic from Real life Groundwater samples, J. of Env.Sc. and Health Part, 40, 227-2246.

2. Lamsal, N and Pradhananga, R.R; 2009 Adsorption of Cd(II) from aqueous solution by charcoal derived from Lapsi (Choerospondias axillaris) seeds, St. Xavier's Journal of Science, vol 1, issue 1, 19.

3. March, H and Rodriguez-Reinoso, F; 2006 Activated Carbon, Elsevier, Amsterdam.

4. National Arsenic Steering Committee (NASC/UNICEF)2007, Report on blanket tube well testing in Sunsari, Bara, Dhanusha, Kailali and Kachanpur district -2007. A report prepared by NASC/UNICEF by Genesis consultancy (P) Ltd (unpublished), Kathamadu.

5. Panthi. S.R, Sharma S, and., Mishra A.K.,2006 : Recent status of arsenic contamination in ground water of Nepal, Kathmandu University of Journal of Science, Engineering and Technology; II(1), 1-11.

6. Paudel, K.C, Eder,R, Paar, E, Pieber, K; 2002 :Chemical composition of Lapsi (Choerospondias axillaris) fruit from Nepal, Journal Mitteilungen Klosterneuburg,52,45-53.

7. Reed,B.E ,.Vaughan R and L.Jiang L; 2000: As(III), As(V), Hg and Pb Removal by Fe-oxide Impregnated Activated Carbon, Journal of Environmental Engineering;, 126(9), 869-873. 
8. Vaishya ,R.C and.Gupta S.K; 2003 Arsenic Removal from Ground Water by Iron Impregnated Sand, Journal of Environmental Engineering, 129(1), 89-92).

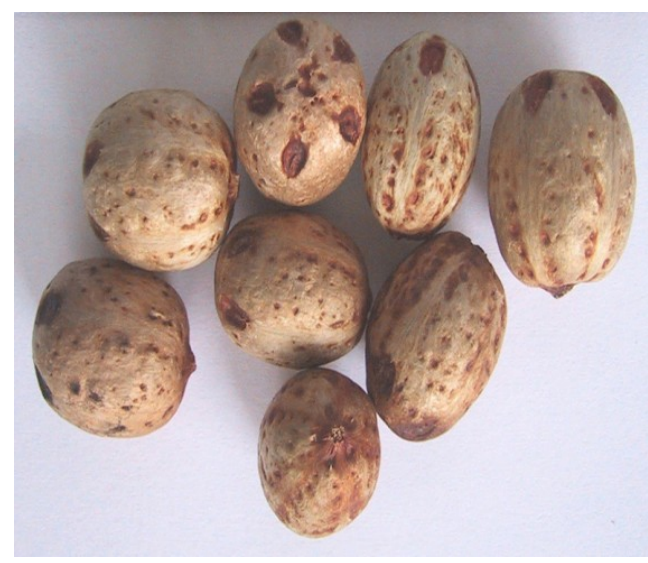

Figure 1: Lapsi Seed Stones

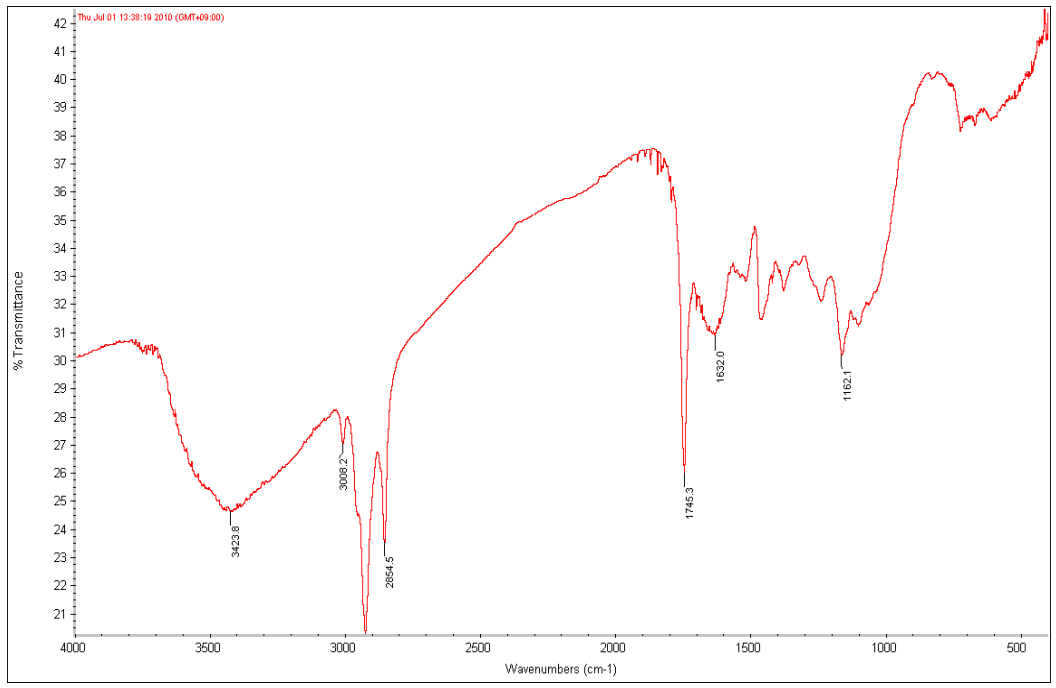

Figure 2: FTIR spectra of Lapsi stone powder 


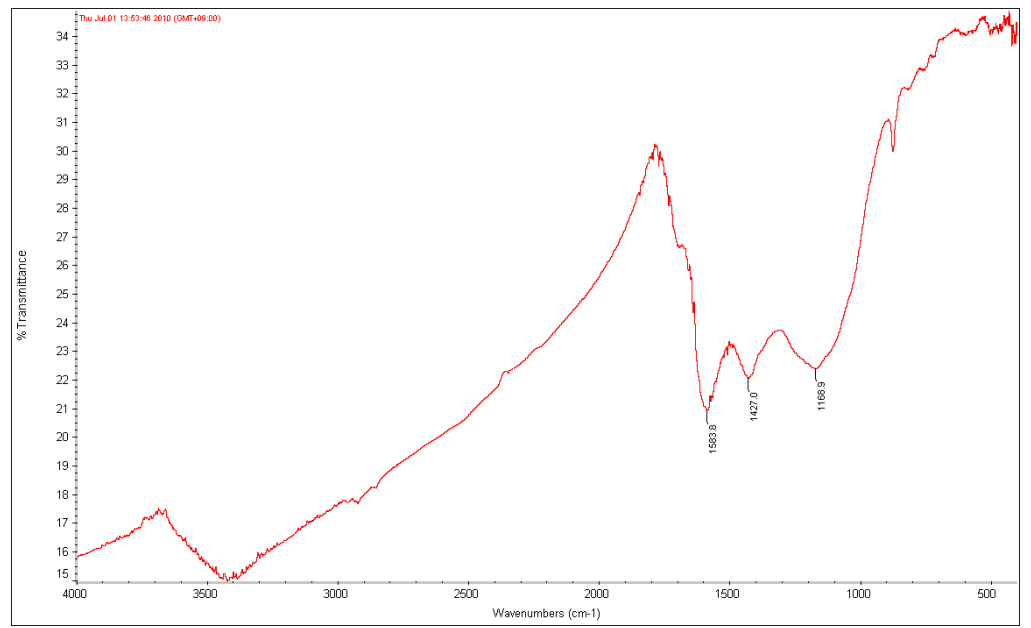

Figure 3: FTIR spectra of activated carbon prepared from Lapsi stone seed

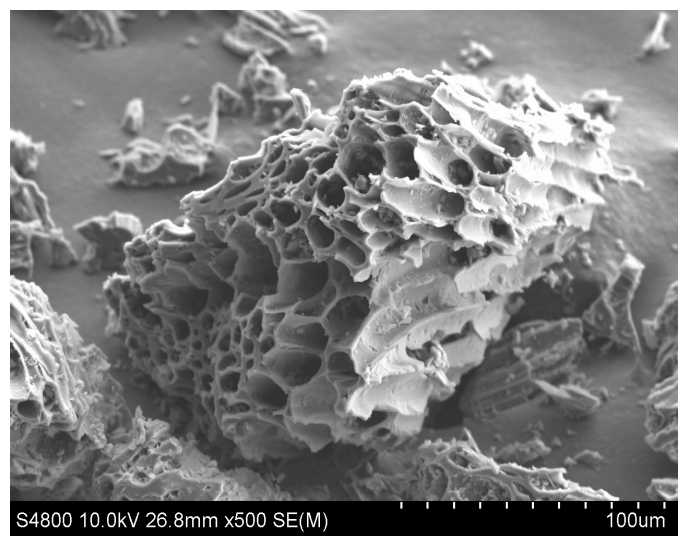

Figure 4. SEM image of activated carbon 


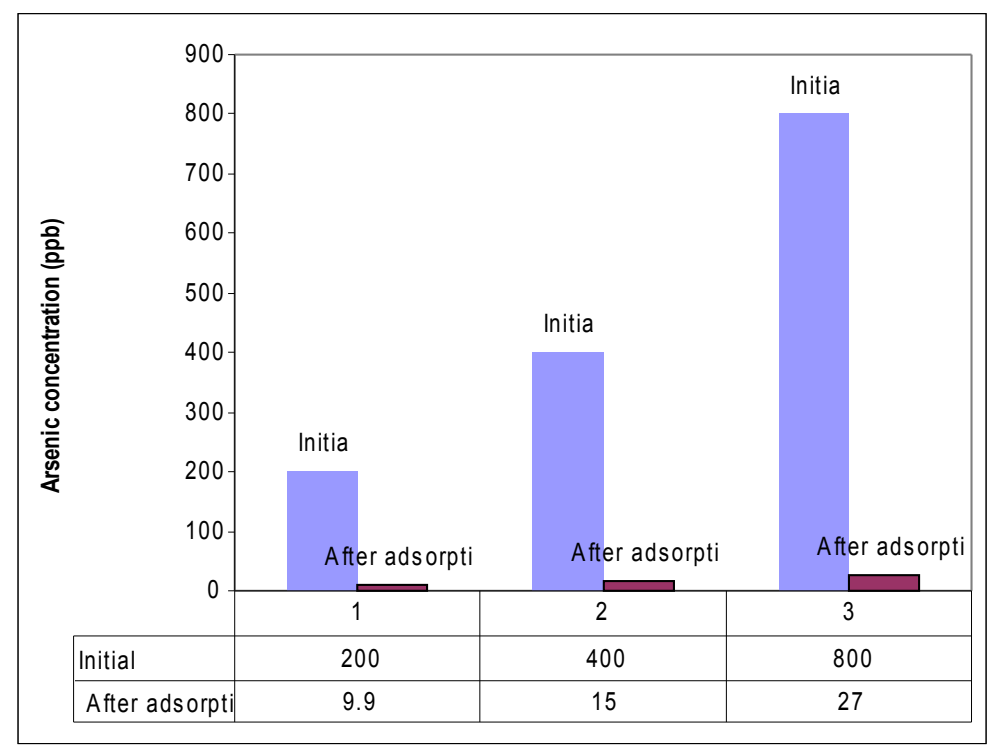

Figure 5: The decrease in arsenic concentration after adsorption.

Table 1: Proximate analysis of Lapsi seed stone powder and concentration of surface functional group in Lapsi seed stone power.

\begin{tabular}{|l|l|l|}
\hline S.N. & \multicolumn{1}{|c|}{ Characteristics } & Value \\
\hline 1 & Ash Content(\%) & 2.7 \\
\hline 2 & Moisture Content(\%) & 0.24 \\
\hline 3 & Fixed Carbon(\%) & 32.8 \\
\hline S.N. & Functional groups & meq g $^{-1}$ \\
\hline 1 & & \\
\hline 2 & Carboxylic & 0.45 \\
\hline 3 & Lactones & 0.30 \\
\hline & Phenol & 0.50 \\
\hline
\end{tabular}


Table 2: Iodine number of carbon prepared from Lapsi seed stone in different conditions.

\begin{tabular}{|l|l|c|}
\hline & LSP : $\mathrm{ZnCl}_{2}$ & Iodine $\mathrm{No}(\mathrm{mg} / \mathrm{g})$ \\
\hline a) & $1: 1$ carbonized in $\mathrm{N}_{2}$ at $400^{\circ} \mathrm{C}$ & 791 \\
\hline b) & $1: 2$ carbonized in $\mathrm{N}_{2}$ at $400^{\circ} \mathrm{C}$ & 871 \\
\hline c) & $2: 1$ carbonized in $\mathrm{N}_{2}$ at $400^{\circ} \mathrm{C}$ & 597 \\
\hline d) & $4: 1$ carbonized in $\mathrm{N}_{2}$ at $400^{\circ} \mathrm{C}$ & 381 \\
\hline e) & $1: 1$ carbonized in $\mathrm{N}_{2}$ at $800^{\circ} \mathrm{C}$ & 898 \\
\hline
\end{tabular}

